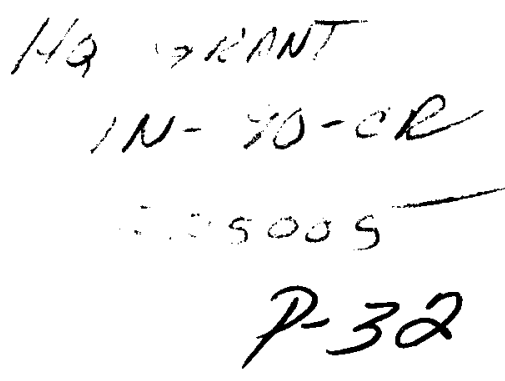

\title{
Silicon Chemistry in Interstellar Clouds
}

\author{
William D. Langer
}

AT\&T Bell Laboratories and New York University

\author{
A. E. Glassgold \\ New York University \\ NAEW 630 \\ Received May 26, 1989
}




\begin{abstract}
Interstellar $\mathrm{SiO}$ was discovered shortly after $\mathrm{CO}$ but it has been detected mainly in high density and high temperature regions associated with outflow sources. We present a new model of interstellar silicon chemistry that explains the lack of $\mathrm{SiO}$ detections in cold clouds and contains an exponential temperature dependence for the $\mathrm{SiO}$ abundance. A key aspect of the model is the sensitivity of $\mathrm{SiO}$ production by neutral silicon reactions to density and temperature, which arises from the dependence of the rate coefficients on the population of the excited fine structure levels of the silicon atom. This effect was originally pointed out in the context of neutral reactions of carbon and oxygen by Graff, who noted that the leading term in neutral atom-molecule interactions involves the quadrupole moment of the atom. Similar to the case of carbon, the requirement that $\mathrm{Si}$ has a quadrupole moment requires population of the $J=1$ level, which lies $111 \mathrm{~K}$ above the $J=0$ ground state and has a critical density $n_{c r} \geq 10^{6} \mathrm{~cm}^{-3}$. The $\mathrm{SiO}$ abundance then has a temperature dependence proportional to $\exp (-111 / T)$ and a quadratic density dependence for $n<n_{c r}$. As part of the explanation of the the lack of $\mathrm{SiO}$ detections at low temperatures and densities, our model also emphasizes the small efficiencies of the production routes and the correspondingly long times needed to reach equilibrium. Measurements of the abundance of $\mathrm{SiO}$, in conjunction with theory, can provide information on the physical properties of interstellar clouds such as the abundances of oxygen bearing molecules and the depletion of interstellar silicon.
\end{abstract}

Subject headings: interstellar: abundances - interstellar: molecules - molecular processes 


\section{INTRODUCTION}

Interstellar $\mathrm{SiO}$ was detected at $\mathrm{mm}$ wavelengths (Wilson et al. 1971) shortly after the discovery of CO (Wilson, Jefferts, and Penzias 1970). Since then, $\mathrm{CO}$ has been observed to be the most widely distributed molecule other than $\mathrm{H}_{2}$ in the interstellar medium. In contrast, $\mathrm{SiO}$ has been detected mainly in regions with high density and temperature associated with outflows from young stellar objects. Although silicon is likely to be strongly depleted on dust grains in dense clouds and $\mathrm{SiO}$ requires a higher density to excite than $\mathrm{CO}$, the almost complete lack of detections in quiescent regions cannot be understood solely in these terms. In this paper, we explain the lack of extensive $\mathrm{SiO}$ detections in terms of the sensitivity of its production by neutral silicon reactions to density and temperature, an effect directly associated with the excitation of the atomic fine structure levels (Graff 1989).

Interstellar silicon chemistry was first discussed in detail by Turner and Dalgarno (1977); other early work was carried out by Solomon and Klemperer (1971), Prasad and Huntress (1980) and Millar (1980). Silicon chemistry in shocks has been studied by Hartquist, Oppenheimer, and Dalgarno (1980) and more recently by Neufeld and Dalgarno (1989). Circumstellar silicon chemistry has been investigated by Scalo and Slavsky (1980) and Clegg et al. (1983). Recent theoretical and experimental studies of silicon reactions and new astronomical observations now provide the stimulation to develop further the interstellar chemistry of silicon.

From radio observations it is apparent that the interstellar chemistry of silicon differs from that of carbon, oxygen, nitrogen, and sulfur. The elemental abundance of $\mathrm{Si}$ is twice that of $\mathrm{S}$ and only an order of magnitude less than $\mathrm{C}, \mathrm{N}$, or $\mathrm{O}$. Yet these species occur in many molecules in widely distributed interstellar molecular clouds whereas gas phase silicon is detected only as $\mathrm{SiO}$ and $\mathrm{SiS}$ (Morris et al. 1975, Irvine et al. 1986) and then only in hot dense regions perturbed by star formation. (These two molecules are also observed in the circumstellar envelopes of highly evolved red giants; $\mathrm{SiC}$ and $\mathrm{SiC}_{2}$ have recently been detected in IRC +10216 (Thaddeus, Cummins, and Linke 1984; Cernicharo et al. 1989)). To address the issue of the dependence of $\mathrm{SiO}$ on temperature, Ziurys, Friberg, and Irvine (1989) searched for its $J=2-1$ emission from both cold as well as hot molecular gas. Despite the fact that the observations of the colder regions were made down to very 
low noise levels, $\mathrm{SiO}$ was detected only in sources with kinetic temperatures greater than $30 \mathrm{~K}$. Because the dipole moment of $\mathrm{SiO}$ (3.1 Debye) is much larger than that of $\mathrm{CO}$, the $\mathrm{SiO}$ emission arises from dense regions, typically with $n\left(\mathrm{H}_{2}\right) \geq 10^{4}-10^{5} \mathrm{~cm}^{-3}$. Moreover, in the sample considered by Ziurys, Friberg, and Irvine (1989), all but one of the $\mathrm{SiO}$ detections were made in or near outflows from young stellar objects and in the supernova remnant IC 443. To determine the abundance variation with temperature, Ziurys, Friberg, and Irvine (1989) compared the SiO column densities with those of HCN, another molecule requiring high density excitation and found primarily in dense regions but not manifesting any strong temperature sensitivity. Over the temperature range from roughly $15 \mathrm{~K}$ to $200 \mathrm{~K}$, they found that the relative abundance of $\mathrm{SiO}$ varies roughly as $\exp (-90 / T)$.

The observations of Ziurys, Friberg, and Irvine (1989) have prompted us to find a theoretical basis for a temperature depedent $\mathrm{SiO}$ abundance. No such temperature sensitivity is known in interstellar carbon chemistry and earlier silicon chemical models do not contain any strong temperature effects at low temperatures. However, recent theoretical work by Graff (1989) shows how the neutral reaction rates of carbon and oxygen atoms, which depend on the population, ordering, and spacing of the atomic fine structure levels, could have a strong temperature dependence. In the case of carbon, with a $J$ $=0$, symmetric, ground state, strong interactions with other neutral systems require significant population of the excited states, the first of which lies at $23.6 \mathrm{~K}$ above the ground state. The resultant temperature variation of the carbon chemistry may not be very pronounced because of the small energy level spacing relative to the kinetic temperature of clouds and also because of the dominance of many other chemical pathways. Oxygen, with opposite fine structure, does not show this behavior. However, silicon has the same finestructure ordering as carbon but with larger separations: the first level is at $111 \mathrm{~K}$ and the second at $321 \mathrm{~K}$. In this paper we propose that $\mathrm{SiO}$ in shielded regions is formed mainly by neutral reactions of $\mathrm{Si}$ atoms in the $J=1$ level with $\mathrm{OH}$ and $\mathrm{O}_{2}$. By applying Graff's ideas, we find that the interstellar $\mathrm{SiO}$ abundance contains an exponential temperature dependence. We also find that the $\mathrm{SiO}$ abundance is sensitive to density because the fine structure levels of $\mathrm{Si}$ are likely to be be sub-thermally populated at densities less than $10^{4}-10^{5} \mathrm{~cm}^{-3}$. Our results explain the absence of $\mathrm{SiO}$ detections in cold, dark clouds by Ziurys et al. Whether or not the the predicted temperature is 
the same as reported by these authors is less certain because the conditions for the applicability of our model may not be satisfied for the sources they discussed.

\section{SILICON CHEMISTRY}

Although much basic laboratory and theoretical information on astrophysically interesting silicon compounds is lacking, we are in a better position than earlier investigators to evaluate the various reaction pathways. Some of the key neutral reactions were actually measured more than a decade ago (Husain and Norris 1978, Swearengen, Davies, and Niemcyzk 1978). Important recent progress includes the measurement of silicon ion-molecule reaction rates (e.g. Bohme, Wlodek, and Fox 1988) and the development of techniques for the extrapolation of room temperature rates to lower temperatures (e.g., Clary 1988, Graff 1989). Advances have also been made in the thermal-chemical data base. For example, the data for silicon hydrides (Curtiss and Pople 1988 and references therein) imply that all reactions of $\mathrm{H}_{2}$ with both neutral and charged mono-silicon hydrides with up to four $\mathrm{H}$ atoms are endothermic. Hence the first-stage species in the ion-molecule chemistry of silicon, $\mathrm{SiH}^{+}$and $\mathrm{SiH}_{2}^{+}$, will not be hydrogenated further and may in fact be destroyed by molecular hydrogen. Even if they are not destroyed in this way, they provide relatively weak pathways to heavier silicon-bearing molecules, in contrast with interstellar carbon chemistry where hydrides provide efficient routes for the synthesis of $\mathrm{CO}$ and other molecules.

The most important feature of our chemical model is the population dependence of the reaction rates of atomic silicon with the neutral species, $\mathrm{OH}$ and $\mathrm{O}_{2}$. Graff (1989) has recently investigated neutral atom reactions at very low temperatures, which are dominated by the long-range interaction of the atomic quadrupole with the dipole or quadrupole moment of the reactant radical or molecule. The low temperature behavior of these reaction rate coefficients is sensitive to the population of the ground state fine structure levels, which determines the atomic quadrupole moment. Graff illustrates the effect by comparing reactions of $\mathrm{O}$ and $\mathrm{C}$ atoms with the radicals $\mathrm{OH}$ and $\mathrm{CH}$. Because these atoms have opposite fine-structure orderings (Table 1), their low-temperature reaction rate coefficients are very different: oxygen will interact strongly with neutral radicals and molecules and carbon weakly below $20 \mathrm{~K}$. Graff suggests that the same principles apply to nen- 
actions of other atoms important in the interstellar medium and we list some of the relevant physical parameters in Table 1 . We omit nitrogen because its $(2 p)^{3}{ }^{4} S_{1 / 2}$ ground state has no fine structure. Because its quadrupole moment also vanishes, we speculate that $N$ reacts the weakest of all the abundant heavy atoms unless other dynamical effects govern its low temperature reactivity.

We extend Graff's ideas to the silicon atom reactions with radicals and molecules that are important in interstellar clouds. The fine structure level ordering of silicon is similar to carbon, but the spacing is larger: $E_{10}=111 \mathrm{~K}$ and $E_{21}=321 \mathrm{~K}$ (Table 1 ). Thus we expect these reaction rates to be proportional to $\exp (-111 / T)$ at low temperature. Carbon atom reactions will be governed by a similar population factor but, because of the smaller level spacing, significant effects can only be expected for cold clouds with $T<15 \mathrm{~K}$. The silicon atom reactions also depend on density because the fine structure level population in interstellar clouds may not be in thermal equilibrium. For the temperatures of interest here, $T<200 \mathrm{~K}$, the effects of the $J=2$ level can be ignored and statistical equilibrium theory gives the following result for the the total steady state fractional population of the first excited level of $\mathrm{Si}$

$$
p_{1}=3\left(n /\left[n\left(1+3 \exp \left(-T_{10} / T\right)+n_{c r}\right]\right) \exp \left(-T_{10} / T\right)\right.
$$

where $n_{c r}=A_{10} / c_{10}$ is the critical density for the $J=1-0$ transition, assumed to be optically thin, $A_{10}$ is the spontaneous decay probability, and $c_{10}$ is the collisional de-excitation rate coefficient for the $J=1-0$ transition. Recent calculations of the de-excitation rate coefficient of the corresponding collisions of $\mathrm{He}$ atoms and $\mathrm{H}_{2}$ molecules with $\mathrm{O}$ atoms (Monteiro and Flower 1986, Flower 1989) indicate that $c_{10}<10^{-11} \mathrm{~cm}^{3} \mathrm{~s}^{-1}$ for $T<100 \mathrm{~K}$ and $c_{10} \ll c_{21}, c_{20}$. In the absence of similar calculations for $\mathrm{Si}$, we use the results for $\mathrm{O}$ as a guide. If the $\mathrm{H}_{2}+\mathrm{Si}$ rate coefficient $c_{10}=10^{-11} \mathrm{~cm}^{3} \mathrm{~s}^{-1}$ for $T<100 \mathrm{~K}$, the critical density for the $J=1-0$ transition is $8 \times 10^{5} \mathrm{~cm}^{-3}$. The corresponding critical density for the $J=2-1$ transition would be at least 10 times smaller and might give interesting physical effects at low densities and $T>100 \mathrm{~K}$.

Table 2 lists the key reactions in our model of the silicon chemistry of interstellar clouds. We assume that the clouds are well shielded from external stellar and interstellar ultraviolet radiation. We list the adopted rate 
coefficients and give references to laboratory measurements if they exist. Otherwise we follow standard practice and conventional wisdom in estimating rate coefficents. If the rate coefficient depends on temperature, we give the exponent $n$ if it follows a power law (in $T^{n}$ ) or indicate by "exp" that the rate has the exponential temperature dependence $\exp (-111 / T)$ associated with silicon atom reactions. For brevity we omit all endothermic reactions. They are unimportant for the low temperature regions under consideration here but they are crucial for shock and other high temperature chemistry. In the following paragraphs, we discuss the background for the several classes of reactions listed in Table 2. For ion-molecule reactions with neutrals with large dipole moments, we use $n=-0.6$, following the discussion of Clary (1988).

\section{Neutral Reactions}

We consider three neutral reactions in the synthesis of silicon molecules from $\mathrm{Si}$ and the most abundant oxygen species other than $\mathrm{CO}$ (for which the relevant reactions are endothermic). Although the reaction of $\mathrm{Si}$ with $\mathrm{H}_{2} \mathrm{O}$ is exothermic, we expect it to have a large enough activation energy to make it unimportant at low temperatures. The primary neutral reactions for the synthesis of $\mathrm{SiO}$ are reactions 1 and 2 of Table 2 ,

$$
\begin{aligned}
\mathrm{Si}+\mathrm{OH} & \rightarrow \mathrm{SiO}+\mathrm{H} \\
\mathrm{Si}+\mathrm{O}_{2} & \rightarrow \mathrm{SiO}+\mathrm{O}
\end{aligned}
$$

Only the rate coefficient for reaction 2 has been measured and here the two room temperature experiments give very different results. Swearengen et al. (1978) suggest that the larger value, obtained with a flash photolysis technique is incorrect because of heating or the production of other reactive species. In this paper we adopt the smaller rate coefficient. Theoretical considerations support this choice. Because $\mathrm{O}_{2}$ does not have a permanent electric dipole moment, the leading term in the $\mathrm{Si}-\mathrm{O}_{2}$ interaction is of the quadrupole-quadrupole type, which leads to a reduction in the Langevin rate coefficient by an order of magnitude (Graff 1989). Both reactions 1 and 2 will be reduced at low temperatures by the effects discussed above and expressed by equation (1).

Applying the results of Graff (1989) to $\mathrm{Si}$, we write the rate coefficients 
for these reactions as

$$
k_{i}=\frac{1}{3} k_{i}(\infty) p_{1}
$$

where $k_{i}(\infty)(i=1,2)$ is the value at high temperatures (relative to the fine-structure splitting). We have taken the fraction of the $J=1$ states that contributes to the reaction to be $1 / 3$ and we have ignored any residual interactions associated with the $J=1-0$ state, again following Graff. Even with the smaller rate coefficient, reaction 2 is probably the dominant $\mathrm{SiO}$ production process because of the large abundance expected for $\mathrm{O}_{2}$ relative to $\mathrm{OH}$. There is only one fairly weak route to $\mathrm{SiO}_{2}$ (reaction $3, \mathrm{SiO}+\mathrm{OH}$ ) because the reaction of $\mathrm{SiO}$ and $\mathrm{O}_{2}$ is endothermic.

\section{Cosmic Ray Induced Photodestruction}

Although neutral reactions occupy the central role in our chemical model, cosmic rays are also important. In addition to directly ionizing hydrogen and helium, they generate UV radiation by inelastic electron scattering from $\mathrm{H}_{2}$ which photoionizes Si and dissociates silicon molecules (Prasad and Tarafdar 1983; Sternberg, Dalgarno, and Lepp 1987; Gredel, Lepp, and Dalgarno 1987). The last group of authors finds that a cosmic ray ionization rate $\zeta$ (defined for $\mathrm{H}_{2}$ ) leads to destruction rates for interstellar molecules that are of order $10^{2}-10^{3} \zeta$, depending on the photodestruction cross section. We have made estimates for silicon species using the UV emission spectrum given by Gredel et al., which spans the range from $900-1650 \AA$. We have estimated the rate for $\mathrm{Si}$, with ionization threshold at $1520 \AA$, by scaling the result of Gredel et al. for C, using the Si photoionization cross section (Hudson, 1971) and taking the grain albedo as 0.5 . The result, $G_{\text {cruv }}=3 \times 10^{-14} \mathrm{~s}^{-1}$ is 3 times larger than for $\mathrm{C}$ because the $\mathrm{Si}$ photoionization cross section matches better the strong UV emission by $\mathrm{H}_{2}$ near 1500 and $1250 \AA$. If the albedo is taken to be 0.9 , the rate would be 5 times larger. Our estimates for $\mathrm{SiO}$ and $\mathrm{SiO}_{2}$ are much less certain because we know little more than the photodissociation thresholds of these species, 1510 and $2650 \AA$, respectively.

\section{Ion-Molecule Reactions}

Pathways to $\mathrm{SiO}$ formation can be initiated by radiative association of $\mathrm{Si}^{+}$with $\mathrm{H}_{2}$ (reaction 8 ) and by the two exothermic reactions of $\mathrm{Si}^{+}$with $\mathrm{OH}$ and $\mathrm{H}_{2} \mathrm{O}$, (reactions 9 and 10 in Table 2). It is noteworthy that all of the measured ion-molecule reaction rates listed in Table 2 are an order 
of magnitude less than the Langevin rate. Despite this fact, we ignore any possible activation energies as is customary in dealing with the low temperature behavior of ion-molecule reaction rates. Only an upper limit is reported for reaction 9 and it can be ignored. The thermal-chemical data needed to determine whether the reaction $\mathrm{SiO}_{2}^{+}+\mathrm{H}_{2} \rightarrow \mathrm{SiO}_{2} \mathrm{H}^{+}+\mathrm{H}$ (reaction 12) is exothermic is missing at this time. The corresponding reactions for $\mathrm{CO}_{2}^{+}$and $\mathrm{SO}_{2}^{+}$do occur (Anicich and Huntress 1986). However, this point is not very important here because the production of $\mathrm{SiO}_{2}^{+}$is probably weak.

The most important ions for destroying $\mathrm{SiO}$ and $\mathrm{SiO}_{2}$ are $\mathrm{C}^{+}$and $\mathrm{He}^{+}$. We have introduced characteristic branching ratios for the various channels that arise when $\mathrm{He}^{+}$destroys $\mathrm{SiO}$ and $\mathrm{SiO}_{2}$. Many reactions of $\mathrm{He}^{+}$with other neutral molecules have been measured (Anicich and Huntress 1986) and serve as the basis for the following estimates. Because charge exchange is generally found to be weak (and frequently does not occur with oxides), we argue that these branchings are small $\left(B_{3}\right.$ and $\left.b_{4}<0.1\right)$. Measurements for $\mathrm{CO}$ and $\mathrm{NO}$, suggest that, for $\mathrm{SiO}, \mathrm{Si}^{+}$rather than $\mathrm{O}^{+}$is favored $\left(B_{2} \sim 1\right.$ and $B_{1}<0.1$ ). Similarly, data for $\mathrm{CO}_{2}$ and $\mathrm{SO}_{2}$ suggest that the dominant branch for $\mathrm{SiO}_{2}$ is $\mathrm{SiO}^{+}$but that $\mathrm{Si}^{+}$and $\mathrm{O}^{+}$may be produced $20 \%$ of the time. For numerical estimates, we adopt $b_{1}=0.8, b_{2}=0.1, b_{3}=0.05$, and $b_{4}=0.05$ and $B_{1}=0.8, B_{2}=0.2$, and $B_{3}=0.1$.

\section{Charge Exchange and Neutralization}

Charge exchange with neutral atoms is potentially an important destruction mechanism for $\mathrm{Si}^{+}$but there is considerable uncertainty in the rate coefficients at the temperatures of interstellar clouds (e.g., see the review by Dalgarno 1988). We have followed the guidelines and estimates of Péquignot and Aldrovandi (1986) in assuming that $\mathrm{Si}^{+}$charge exchanges rapidly with the following heavy atoms: $\mathrm{Mg}, \mathrm{Fe}, \mathrm{Al}, \mathrm{Ca}$, and $\mathrm{Ni}$. Of course all of these elements are likely to be strongly depleted in grains, thereby reducing the effect. However, $\mathrm{Si}^{+}$can be efficiently neutralized by the population of negatively charged solid particles and large molecules such as polycyclic aromatic hydrocarbons expected to exist in shielded interstellar clouds (e.g., see the review by Omont 1986). Without commiting ourselves to the exact identity of this component of the interstellar medium, we have included their neutralization of $\mathrm{Si}^{+}$as reaction 28 in Table 2 , denoting them by the symbol $\mathrm{PM}^{-}$. The relatively small abundance of such "particles" is offset by the 
large cross section for neutralization, and this process is likely to dominate charge exchange with neutral atoms.

\section{CHEMICAL MODEL}

The production pathways for the chemistry discussed in $\S$ II are represented schematically in Figure 1. The dominant pathways for the synthesis of $\mathrm{SiO}$ and $\mathrm{SiO}_{2}$ involve the reactions of $\mathrm{Si}$ with $\mathrm{OH}$ and $\mathrm{O}_{2}$ and $\mathrm{Si}^{+}$with $\mathrm{H}_{2} \mathrm{O}$. In this section, we derive approximate, analytic formulae which exhibit the dependence of the various silicon species abundances on temperature, density, and cosmic ray ionization rate.

As mentioned in $\S \mathrm{II}$, the production of silicon hydrides is extremely inefficient. The $\mathrm{SiH}^{+}$produced by proton transfer from $\mathrm{H}_{3}^{+}$to $\mathrm{Si}$ does not react with $\mathrm{H}_{2}$ and most of it recombines to $\mathrm{Si}$ again. The only other significant route to $\mathrm{SiH}$, radiative association (reaction 8 ) followed by dissociative recombination of $\mathrm{SiH}_{2}^{+}$, is also weak, as we will show below. Therefore we initially neglect the silicon hydrides and their ions because they are relatively unimportant as progenitors of $\mathrm{SiO}$ and $\mathrm{SiO}_{2}$, except at very low temperatures.

The $\mathrm{SiO}^{+}$ion has negligible abundance because it reacts rapidly with $\mathrm{H}_{2}$ (reaction 11) to form $\mathrm{SiOH}^{+}$. It is unlikely that $\mathrm{SiOH}^{+}$interacts further with $\mathrm{H}_{2}$; instead it recombines to form $\mathrm{SiO}$. Thus the interaction of $\mathrm{Si}^{+}$with $\mathrm{OH}$ leads to the following ionic pathways to $\mathrm{SiO}$ :

$$
\begin{aligned}
\mathrm{Si}^{+}+\mathrm{OH} & \rightarrow \mathrm{SiO}^{+}+\mathrm{H} \\
\mathrm{SiO}^{+}+\mathrm{H}_{2} & \rightarrow \mathrm{SiOH}^{+}+\mathrm{H} \\
\mathrm{SiOH}^{+}+\mathrm{e} & \rightarrow \mathrm{SiO}+\mathrm{H}
\end{aligned}
$$

The corresponding neutral pathways are initiated by reactions 1 and 2 .

In the approximation of ignoring the silicon hydrides, we solve for the steady state silicon abundances using the three balance equations for $\mathrm{Si}^{+}$, $\mathrm{SiO}$, and $\mathrm{SiO}_{2}$ and the conservation condition for all gas phase silicon. The steady state equations for the fractional abundances of species $\mathrm{X}, x(\mathrm{X})=$ $n(\mathrm{X}) / n\left(\mathrm{H}_{2}\right)$, formed from species $\mathrm{Y}$ and $\mathrm{Z}$ are written in the form

$$
D x(\mathrm{X})=P x(\mathrm{Y}) x(\mathrm{Z})
$$

where $\mathrm{D}$ and $\mathrm{P}$ are appropriate destruction and production factors. The 
balance equations are given below and the P's and D's are listed in Table 3:

$$
\begin{gathered}
D_{1} x\left(\mathrm{Si}^{+}\right)=P_{4} x(\mathrm{Si})+P_{5} x(\mathrm{SiO})+P_{6} x\left(\mathrm{SiO}_{2}\right) \\
D_{2} x(\mathrm{SiO})=P_{1} x(\mathrm{Si})+P_{2} x\left(\mathrm{Si}^{+}\right)+P_{3} x\left(\mathrm{SiO}_{2}\right) \\
D_{3} x\left(\mathrm{SiO}_{2}\right)=P_{7} x(\mathrm{SiO})
\end{gathered}
$$

Solving these equations yields the following ratios among the silicon species:

$$
\begin{gathered}
x\left(\mathrm{SiO}_{2}\right) / x(\mathrm{SiO})=P_{7} / D_{3} \\
x(\mathrm{SiO}) / x(\mathrm{Si})=\left[P_{1}+P_{2} P_{4} / D_{1}\right] / \Delta
\end{gathered}
$$

where

$$
\Delta=\left[D_{2}-P_{2} P_{5} / D_{1}\right]-\left[P_{7} / D_{3}\right]\left[P_{3}+P_{2} P_{6} / D_{1}\right]
$$

\section{RESULTS}

We use the formulae derived in $\S$ III to estimate the abundances of the silicon species as a function of the relevant astrophysical parameters. The essential nature of the temperature and density dependence can be most clearly understood by first assuming that $\mathrm{SiO}_{2}$ and $\mathrm{SiH}$ can be neglected, which we later show to be a good approximation. The factor $\Delta$ in the denominator of equation (8) then reduces to $\Delta=D_{2}-P_{2} P_{5} / D_{1}$ and the second term can be neglected as long as $x\left(\mathrm{H}_{2} \mathrm{O}\right)<10^{-4}$. Consequently the $\mathrm{SiO} / \mathrm{Si}$ abundance ratio can be written in a form where the contributions to molecule formation by neutral reactions with $\mathrm{Si}$ and ion reactions with $\mathrm{Si}^{+}$ occur additively:

$$
x(\mathrm{SiO}) / x(\mathrm{Si})=R f \exp (-111 / T)+Z
$$

where

$$
\begin{gathered}
R=P_{1}(\infty) / D_{2} \\
Z=P_{2} P_{4} / D_{1} D_{2} \leq \frac{1}{2} P_{2} / D_{1} \\
f=n /\left[n(1+3 \exp (-111 / T))+n_{c r}\right] .
\end{gathered}
$$

The factors $R, Z$, and $f$ depend only weakly on temperature. The symbol $P_{1}(\infty)$ is the production factor $P_{1}$ in Table 3 evaluated at $300 \mathrm{~K}$. Taking into account the conservation condition for silicon yields

$$
x(\mathrm{SiO}) / x_{\mathrm{Si}}=[R f \exp (-111 / T)+Z] /[1+R f \exp (-111 / T)+Z]
$$


where $x_{\mathrm{Si}}$ is the total abundance of all gas phase silicon species. This equation has an exponential temperature dependence for $T_{1}<T<T_{2}$ if $R f$ is not very large and $Z \ll 1$. We can estimate $T_{1}$ and $T_{2}$ by ignoring the term $3 \exp (-111 / T)$ in equation 12 and obtain

$$
\begin{gathered}
T_{1}=111 /[\ln (R f / Z)] \\
T_{2}=111 /[\ln (R f /(1+Z))]
\end{gathered}
$$

if $R f /(1+Z)>1$; otherwise $T_{2}=\infty$. Substituting typical values of the parameters into $R, f$, and $Z$, expressing them in convenient units, and assuming that $c_{10}=10^{-11} \mathrm{~cm}^{3} \mathrm{~s}^{-1}$, these quantities become

$$
\begin{gathered}
R \sim 16 n_{5}\left[x\left(\mathrm{O}_{2}\right)_{-6}+0.1 x(\mathrm{OH})_{-8}\right] / \zeta_{-17} \\
f \sim n_{5} /\left(n_{5}+8.2\right) \\
Z \sim 0.0025 x\left(\mathrm{H}_{2} \mathrm{O}\right)_{-6} /\left[x\left(\mathrm{PM}^{-}\right)_{-7} T^{-0.5}+0.25 x(\mathrm{~A})_{-6}+0.005 x\left(\mathrm{H}_{2} \mathrm{O}\right)_{-6}\right]
\end{gathered}
$$

where we have introduced the notation, $n_{5}=n / 10^{5} \mathrm{~cm}^{-3}$, etc.

According to equation 13 and the approximate forms for $R, Z$, and $f$, the abundance of $\mathrm{SiO}$ is sensitive to the abundances of $\mathrm{OH}, \mathrm{O}_{2}$ and $\mathrm{H}_{2} \mathrm{O}$. At this time there is little observational information concerning the abundances of $\mathrm{O}_{2}$, and $\mathrm{H}_{2} \mathrm{O}$ because of the extreme difficulty in observing the emission of these molecules from the ground. Indeed, the apportioning of oxygen among the various oxygen-bearing species in molecular clouds is widely considered to be one of the outstanding problems in interstellar chemistry. Radio observations of $\mathrm{OH}$ (e.g., Crutcher 1979, Irvine et al. al. 1986) indicate a range from $10^{-8}-10^{-7}$ for the $\mathrm{OH}$ abundance in clouds with densities $n\left(\mathrm{H}_{2}\right) \leq 10^{4} \mathrm{~cm}^{-3}$. Theory suggests that the $\mathrm{OH}$ abundance decreases with density (Langer and Graedel 1989) and we adopt an intermediate value for estimation purposes, $x(\mathrm{OH})=3 \times 10^{-8}$. Emission from molecular oxygen has not yet been detected and the smallest upper limit, $x\left(\mathrm{O}_{2}\right) \leq 5 \times 10^{-6}$, has been obtained with the isotopic variant, ${ }^{16} \mathrm{O}^{18} \mathrm{O}$, for the $\rho \mathrm{Oph}$ cloud (Liszt and Vanden Bout 1985, Goldsmith et al. 1985). Here we adopt a slightly smaller value $x\left(\mathrm{O}_{2}\right)=3 \times 10^{-6}$ representative of the results of chemical models. Radio observations of $\mathrm{H}_{2} \mathrm{O}$ (and its isotopic variants) involve transitions from highly excited states in hot, dense regions $\left(n\left(\mathrm{H}_{2}\right) \geq 10^{4} \mathrm{~cm}^{-3}, T \geq 10^{2} \mathrm{~K}\right)$ and suggest that $x\left(\mathrm{H}_{2} \mathrm{O}\right) \sim 10^{-5}$. A possible detection of infrared absorption from 
the ground state of $\mathrm{H}_{2} \mathrm{O}$ leads to $x\left(\mathrm{H}_{2} \mathrm{O}\right) \leq 3 \times 10^{-7}-2 \times 10^{-6}$ for the material along the line of sight towards Orion-BN (Knacke, Larson, and Noll 1989). Because $\mathrm{H}_{2} \mathrm{O}$ can be expected to freeze out on grains at relatively high temperatures $\sim 100 \mathrm{~K}$, we expect the $\mathrm{H}_{2} \mathrm{O}$ abundance to vary from region to region and, for estimation purposes, assume that it is in the range from $10^{-8}-10^{-5}$.

The quantities $R f$ and $Z$ are the relative fractions of SiO formed by neutral and ionic reaction pathways, respectively. One or the other must approach unity in order for a substantial fraction of silicon to be converted into molecules in steady state. It is important to note that $R f$ and $Z$ have different dependences on density: $R f \sim n^{2}$ for $n<n_{c r}$ and $Z$ independent of $n$. In order to have efficient production of $\mathrm{SiO}$ at high temperatures by neutral reactions, the density must be $\geq 5 \times 10^{4} \mathrm{~cm}^{-3}$ for the choices made above for the abundances of oxygen-bearing molecules. The quantity $Z$ is a sensitive function of the $\mathrm{H}_{2} \mathrm{O}$ abundance and of the abundances of the species that neutralize $\mathrm{Si}^{+}$. Even for $x\left(\mathrm{H}_{2} \mathrm{O}\right)$ as large as $10^{-5}, Z$ is only $\sim 0.01$ for $T=100 \mathrm{~K}$. Because $Z$ is generally small, $\mathrm{SiO}$ is produced efficiently by neutral reactions in warm, dense clouds, but the role of neutral reactions is significantly reduced in cool clouds by the Boltzmann factor, $\exp (-111 / T)$. More specifically, equation (14) gives the condition that the temperature must satisfy in order for neutral reactions to dominate ionic reactions, i.e., $T>T_{1}$, where $T_{1}$ is determined approximately from equation 14 using the quantity

$$
R f / Z=6.7 \times 10^{3} \frac{n_{5}^{2}}{n_{5}+8.2}\left[T^{-0.5} x\left(\mathrm{PM}^{-}\right)_{-7} \frac{x\left(\mathrm{O}_{2}\right)}{x\left(\mathrm{H}_{2} \mathrm{O}\right)}\right] / \zeta_{-17}
$$

For example, if $x\left(\mathrm{H}_{2} \mathrm{O}\right) \sim x\left(\mathrm{O}_{2}\right)$, then $T_{1} \sim 25 \mathrm{~K}$. Because $\mathrm{H}_{2} \mathrm{O}$ is expected to freeze out on grains at low temperatures, it is reasonable to expect that neutral reactions will continue to dominate production down to very low temperatures. Thus, if $x\left(\mathrm{H}_{2} \mathrm{O}\right) \sim 0.1 x\left(\mathrm{O}_{2}\right), T_{1}$ is reduced to $15 \mathrm{~K}$.

In Figure 2 we plot the solution to equation 13 for the ratio $x(\mathrm{SiO}) / x_{\mathrm{Si}}$ as a function of temperature (plotted as $1 / T$ ) for several values of $R f$ and $Z$. As expected from the above discussion, the fractional $\mathrm{SiO}$ abundance decreases approximately as $\exp (-111 / T)$ if $R f$ is not too large and $Z$ is small. In the case where $R f$ is large, the exponential decrease does not occur until low temperatures, e.g., it starts at $T=50 \mathrm{~K}$ for $R f=10$. For $Z \neq 0$, 
the exponential decrease disappears at low temperatures and the solution goes over to a constant. In the case $R f=1$ and $Z=10^{-3}$, this changeover occurs below $20 \mathrm{~K}$. However, we show below that time dependent effects become important at low temperatures and this leveling out probably does not occur.

Although the contribution of $\mathrm{SiH}$ to $\mathrm{SiO}$ production is usually small, it can become important at low temperatures because $\mathrm{SiH}$ can interact strongly with ground state oxygen atoms. The primary path for $\mathrm{SiH}$ formation is radiative association of $\mathrm{Si}^{+}$with $\mathrm{H}_{2}$ (reaction 8 ) followed by recombination with electrons (reaction 24). It is destroyed primarily by $O$ (reaction 4 ) as long as $x(O)>10^{-6}$. Under these conditions the $\mathrm{SiH}$ abundance is given approximately by the following expression,

$$
x(\mathrm{SiH}) \sim 5 \times 10^{-3} x\left(\mathrm{Si}^{+}\right) / x(\mathrm{O})_{-4} .
$$

Because they are both proportional to the abundance of $\mathrm{Si}^{+}$, we can easily compare the efficiency of $\mathrm{SiO}$ production by $\mathrm{SiH}$ with that of the ionic pathway involving $\mathrm{Si}^{+}$and $\mathrm{H}_{2} \mathrm{O}$ (reaction 10 ). Production by $\mathrm{SiH}$ needs to be considered only if $x\left(\mathrm{H}_{2} \mathrm{O}\right)<2 \times 10^{-7}$.

It is important to examine the time required to synthesize the silicon molecules. It is apparent from the above solutions that efficient conversion of silicon atoms into molecules only takes place at high densities. Thus little $\mathrm{SiO}$ should be produced in the early, low density stages of cloud evolution when $n<10^{4} \mathrm{~cm}^{-3}$. This conclusion can be brought into clearer focus by considering the time for neutral reactions to produce $\mathrm{SiO}$, which can be approximated by

$$
t_{\text {chem }} \simeq\left[\left(k_{1}(\infty) x\left(\mathrm{O}_{2}\right)+k_{2}(\infty) x(\mathrm{OH})\right) n f \exp (-111 / T)\right]^{-1}
$$

and can be written in convenient units as

$$
t_{\text {chem }}=3 \times 10^{4} \exp (111 / T) \frac{\left(1+8.2 / n_{5}\right)}{n_{5}\left[x\left(\mathrm{O}_{2}\right)_{-6}+0.1 x(O H)_{-8}\right]} \mathrm{yr}
$$

For $T>100 \mathrm{~K}$, the time required to achieve equilibrium is fairly long at low and intermediate densities, e.g., approximately $3 \times 10^{7}$ yr for $n=$ $10^{4} \mathrm{~cm}^{-3}$ and $x\left(\mathrm{O}_{2}\right)=3 \times 10^{-6}$ and $x(\mathrm{OH})=3 \times 10^{-8}$ and $3 \times 10^{5} \mathrm{yr}$ if 
the density is increased to $n=10^{5} \mathrm{~cm}^{-3}$. Densities greater than $10^{6} \mathrm{~cm}^{-3}$ are required before the neutral reactions can produce $\mathrm{SiO}$ in a time short compared to cloud evolutionary times but, even in this case, the clouds must be warm. The exponential increase of the chemical timescale suggests that, at low temperatures, where ions dominate its production, the abundance of $\mathrm{SiO}$ will be very small. Consequently, we believe that it is unlikely that much $\mathrm{SiO}$ is produced at low temperatures because, not only are the chemical pathways inefficient, but the time to produce near-equilibrium abundances is much longer than the lifetimes of the dense, cold regions of interstellar clouds.

The effects of non-equilibrium chemistry are illustrated in Figure 3 where we show approximate time dependent solutions for $x(\mathrm{SiO}) / x_{\mathrm{Si}}$ as a function of temperature (plotted as $1 / \mathrm{T}$ ) for $R f=1$ and for $n=5 \times 10^{4} \mathrm{~cm}^{-3}$, $x\left(\mathrm{O}_{2}\right)=3 \times 10^{-6}$, and $x(\mathrm{OH})=3 \times 10^{-8}$. We give solutions at times ranging from $10^{6}$ to $10^{9} \mathrm{yr}$ as well as the steady state solution for $Z=0$. For $t<10^{7} \mathrm{yr}$, the abundances are considerably depressed below the steady state solution at low temperatures $(T<25 K)$. For the case $Z=10^{-3}$ (ionic chemistry included), we also present results at $10^{7}$ years and in steady state. Even though this steady state solution departs from an exponential (and becomes constant) below $20-25 \mathrm{~K}$, the time dependent solution remains nearly exponential down to about $15 \mathrm{~K}$, although with a steeper slope than the function $\exp (-111 / T)$. In the limit of $T \rightarrow 0$, the ionic chemistry time scale becomes $t_{\text {chem }}=3 \times 10^{8} \mathrm{yr}$, independent of density, and probably longer than any relevant dynamical time scale. Figure 4 present additional illustrations of the theory for higher density regions without ionic reactions $(Z=0)$. For $n=10^{6} \mathrm{~cm}^{-3}$ (Fig. 4b), large SiO abundances are achieved for temperatures down to $15 \mathrm{~K}$ within $\sim 10^{6}$ years. For times less than $10^{6}$ years, the abundance has an exponential dependence on temperature.

Finally, we can estimate the $\mathrm{SiO}_{2}$ abundance in warm interstellar clouds of the type considered in our theory. From the equations in $\S$ III we can write in convenient units

$$
x\left(\mathrm{SiO}_{2}\right) / x(\mathrm{SiO}) \sim 0.17 n_{5} x(\mathrm{OH})_{-8} / \zeta_{-17} .
$$

Significant amounts of $\mathrm{SiO}_{2}$ can be produced in warm regions where $\mathrm{SiO}$ is abundant. Using the $\mathrm{OH}$ abundance adopted above, $x(\mathrm{OH}) \sim 3 \times 10^{-8}$, 
we obtain $\mathrm{SiO}_{2} / \mathrm{SiO}$ ratios of order $0.5 n_{5}$. Although $\mathrm{SiO}_{2}$ is not directly observable by radio techniques, it might be possible to detect its protonated ion, $\mathrm{HSiO}_{2}^{+}$, which should have a large dipole moment. We estimate that $\mathrm{HSiO}_{2}^{+} / \mathrm{SiO}_{2} \sim 10^{-3}$.

\section{SUMMARY}

We have developed a model of the gas phase silicon chemistry for shielded, quiescent interstellar clouds in which the $\mathrm{SiO}$ abundance has a strong temperature dependence of the type suggested by Ziurys et al. In this theory, neutral reactions of $\mathrm{Si}$ with $\mathrm{O}_{2}$ and, perhaps, $\mathrm{OH}$ are mainly responsible for producing $\mathrm{SiO}$. These reactions occur only for $\mathrm{Si}$ in excited fine structure levels and require relatively warm conditions, e.g., $T \geq 30 \mathrm{~K}$. Fairly high densities are also necessary to significantly populate the first excited fine structure level of $\mathrm{Si},\left(n\left(\mathrm{H}_{2}\right) \geq 10^{6} \mathrm{~cm}^{-3}\right)$, in order to overcome its rapid spontaneous decay. Ion-molecule reactions are relatively unimportant in shielded regions in producing $\mathrm{SiO}$ and, when they occur, proceed with such low efficiency that very long times are needed to achieve observationally significant values. According to our theory, the production rate of $\mathrm{SiO}$ at low temperatures and low densities is so small that steady state abundances are unlikely to be achieved within cloud evolutionary times.

In our model, the fraction of gas phase silicon in $\mathrm{SiO}$ is sensitive to the density, the $\mathrm{O}_{2}$ and $\mathrm{OH}$ abundances, the total gas phase abundance of silicon, and the critical density for populating the $J=1$ level of $\mathrm{Si}$ (see equations 13 and 16-18). Consequently, in conjuction with observational determinations of the $\mathrm{SiO}$ abundance, it should be possible to use our theory to determine, or at least constrain, presently poorly known physical parameters of appropriate interstellar clouds such as the depletion of silicon and the abundances of $\mathrm{O}_{2}$ and $\mathrm{H}_{2} \mathrm{O}$. For example, measurements of the $\mathrm{SiO}$ abundance in warm, shielded regions could be used to determine the silicon depletion. In the high $T$ limit

$$
x(\mathrm{SiO}) \simeq x_{S_{i}} \frac{R f}{R f+1}
$$

and, because $R f$ must be at least of order unity to produce $\mathrm{SiO}$ efficiently, the $\mathrm{SiO}$ abundance itself measures (to within a factor of a few) the gas phase abundance of silicon. Unfortunately, it is not yet possible to make a quantitative estimate along these lines because the observations discussed by Ziurys 
et al. for warm regions refer to outflow sources or their environs. The abundance of $\mathrm{SiO}$ in these sources is likely to have a significant contribution from the reaction of $\mathrm{Si}^{+}$with $\mathrm{H}_{2} \mathrm{O}$ (equation 10). In this situation, an estimate of the $\mathrm{SiO}$ abundance can be made in the context of a photodissociation region model (Tielens and Hollenbach et al., 1985) by assuming that $\mathrm{SiO}$ is produced by reaction 10 and destroyed by UV radiation at a rate $G(\mathrm{SiO})$ :

$$
x(\mathrm{SiO})=k_{10} n x\left(\mathrm{Si}^{+}\right) x\left(\mathrm{H}_{2} \mathrm{O}\right) / G(\mathrm{SiO})
$$

The $\mathrm{SiO}$ abundance now depends on the depletion factor for silicon, the strength of the radiation field, the density, the $\mathrm{H}_{2} \mathrm{O}$ abundance, and the photodestruction cross section of $\mathrm{SiO}$. Entering reasonable values for these quantities leads to abundances of the same order given by Ziurys et al. for warm, outflow sources, although with considerable uncertainty because of the dependence on so many unknown parameters.

Obtaining constraints for cold, dark clouds is more difficult because the chemistry is almost certainly time-dependent. The steady state expression for the $\mathrm{SiO}$ abundance (equation 13) reduces to

$$
x(\mathrm{SiO}) \simeq Z x_{S i}
$$

in the low temperature limit where ions contribute. Referring to equation 18 for $Z$, we see the potential for obtaining a limit on the $\mathrm{H}_{2} \mathrm{O}$ abundance in cold, dark clouds using the upper limits to the $\mathrm{SiO}$ abundance estimated by Ziurys et al. A low water abundance for cold, dark clouds is consistent with the expectation that $\mathrm{H}_{2} \mathrm{O}$ readily freezes out onto grains during the course of cloud evolution at low temperatures. However, the nondetection of $\mathrm{SiO}$ in these clouds could also arise from severe depletion of silicon species onto grains or the long chemical time scale for the formation of $\mathrm{SiO}$ or a combination of all these effects.

In summary, our theory explains the failure of Ziurys et al. to detect $\mathrm{SiO}$ in dark clouds in terms of the suppression of both the neutral and ionic chemistries, the former because of the low temperature and density and the latter by the freezing out of $\mathrm{H}_{2} \mathrm{O}$. The direct confirmation of the exponential temperature dependence associated with the excitation of the fine structure levels requires further observational studies of warm, shielded clouds. Despite the sensitivity of the theory to many presently unknown reaction rate coefficients and to the physical parameters and chemical abundances of interstellar 
clouds, it does demonstrate the importance of neutral reactions for interstellar silicon chemistry. Our work also illustrates the significance of Graff's ideas on the low temperature behavior of the rate coefficients for the reaction of atoms with molecules and radicals. In focusing in this paper on the most abundant silicon molecule, $\mathrm{SiO}$, we have ignored several interesting problems in interstellar chemistry such as the synthesis of SiS and the abundance of the silicon carbides. We have also not attempted to treat the coupling between the silicon in the gas and solid phases other than to recognize that most of the silicon is incorporated in dust in dense clouds with depletion factor varying from cloud to cloud. These simplifications are justified by the current, preliminary nature of both the theoretical and observational aspects of interstellar silicon chemistry.

Our theory suggest several directions for future research. In order to strengthen the basis of the theory, it would be extremely valuable to remeasure the fundamental neutral reaction, $\mathrm{Si}+\mathrm{O}_{2} \rightarrow \mathrm{SiO}+\mathrm{O}$, as a function of temperature at and below $300 \mathrm{~K}$. Calculations of the collisional de-excitation rate of the $\mathrm{Si}$ fine structure levels by $\mathrm{H}_{2}$ would help quantify the density dependence of the chemistry. Measurements of the $\mathrm{O}_{2}$ and $\mathrm{H}_{2} \mathrm{O}$ abundances would permit interesting tests of the theory based on the close correlation between $\mathrm{SiO}$ and the $\mathrm{O}_{2}$ and $\mathrm{H}_{2} \mathrm{O}$ abundances. More sensitive ground based observations of different types of interstellar clouds are required to establish the density and temperature dependence of the $\mathrm{SiO}$ abundance. One of the goals of such observations should be to confirm the prediction of this paper that the $\mathrm{SiO}$ abundance in dense, shielded clouds varies with temperature and density, primarily through the population of the excited fine structure levels.

One of us (A.E.G) would like to acknowledge partial support of this research by a grant from NASA. The authors are grateful for helpful commments from Dennis Downes, Paul Goldsmith, Michel Guélin, Chris McKee, and Frank Shu. 
Table 1

Fine Structure Energy Levels and Transition Probabilities ${ }^{a}$

\begin{tabular}{crrrcccc}
\hline Atom & $\mathrm{E}_{0} / \mathrm{k}$ & $\mathrm{E}_{1} / \mathrm{k}$ & $\mathrm{E}_{2} / \mathrm{k}$ & $\mathrm{A}_{10}$ & $\mathrm{~A}_{12}$ & $\mathrm{~A}_{21}$ & $\mathrm{~A}_{01}$ \\
\hline $\mathrm{C}$ & 0 & 23.6 & 62.6 & $7.93 \times 10^{-8}$ & & $2.68 \times 10^{-7}$ & \\
$\mathrm{O}$ & 325.9 & 228.1 & 0 & & $8.95 \times 10^{-5}$ & & $1.70 \times 10^{-5}$ \\
$\mathrm{Si}$ & 0 & 111.0 & 321.1 & $8.25 \times 10^{-6}$ & & $4.20 \times 10^{-5}$ & \\
$\mathrm{~S}$ & 825.4 & 571.0 & 0 & & $1.40 \times 10^{-3}$ & & $3.02 \times 10^{-4}$ \\
\hline
\end{tabular}

a The units are $\mathrm{K}$ for energies and $\mathrm{s}^{-1}$ for transition probabilities. 
Table 2

Silicon Chemical Reactions

\begin{tabular}{|c|c|c|}
\hline Reaction & Rate Constant ${ }^{a}$ & T-Dependence \\
\hline 1. $\mathrm{Si}+\mathrm{OH} \rightarrow \mathrm{SiO}+\mathrm{H}$ & $10^{-10}$ & $\exp$ \\
\hline 2. $\mathrm{Si}+\mathrm{O}_{2} \rightarrow \mathrm{SiO}+\mathrm{O}$ & $\begin{array}{r}9 \times 10^{-12 b} \\
2.7 \times 10^{-10 c}\end{array}$ & $\begin{array}{l}\exp \\
\exp \end{array}$ \\
\hline 3. $\mathrm{SiO}+\mathrm{OH} \rightarrow \mathrm{SiO}_{2}+\mathrm{H}$ & $10^{-10}$ & \\
\hline 4. $\mathrm{SiH}+\mathrm{O} \rightarrow \mathrm{SiO}+\mathrm{H}$ & $10^{-10}$ & \\
\hline 5. $\mathrm{CR} \mathrm{UV}+\mathrm{Si} \rightarrow \mathrm{Si}^{+}+e$ & $3 \times 10^{-14 d}$ & \\
\hline 6. $\mathrm{CR} \mathrm{UV}+\mathrm{SiO} \rightarrow \mathrm{Si}+\mathrm{O}$ & $3 \times 10^{-14 d}$ & \\
\hline 7. $\mathrm{CR} \mathrm{UV}+\mathrm{SiO}_{2} \rightarrow \mathrm{SiO}+\mathrm{O}$ & $3 \times 10^{-14 d}$ & \\
\hline 8. $\mathrm{Si}^{+}+\mathrm{H}_{2} \rightarrow \mathrm{SiH}_{2}^{+}+\mathrm{h} \nu$ & $10^{-16}$ & \\
\hline 9. $\mathrm{Si}^{+}+\mathrm{OH} \rightarrow \mathrm{SiO}^{+}+\mathrm{H}$ & $\leq 10^{-11 e}$ & \\
\hline 10. $\mathrm{Si}^{+}+\mathrm{H}_{2} \mathrm{O} \rightarrow \mathrm{SiOH}^{+}+\mathrm{H}$ & $2.3 \times 10^{-10 e}$ & -0.6 \\
\hline 11. $\mathrm{SiO}^{+}+\mathrm{H}_{2} \rightarrow \mathrm{SiOH}^{+}+\mathrm{H}$ & $3 \times 10^{-10 f}$ & \\
\hline 12. $\mathrm{SiO}_{2}^{+}+\mathrm{H}_{2} \rightarrow \mathrm{SiO}_{2} \mathrm{H}^{+}+\mathrm{H}$ & $2 \times 10^{-10}$ & \\
\hline 13. $\mathrm{H}_{3}^{+}+\mathrm{Si} \rightarrow \mathrm{SiH}^{+}+\mathrm{H}_{2}$ & $10^{-9}$ & \\
\hline 14. $\mathrm{HCO}^{+}+\mathrm{Si} \rightarrow \mathrm{SiH}^{+}+\mathrm{CO}$ & $10^{-9}$ & \\
\hline
\end{tabular}


15. $\mathrm{H}_{3}^{+}+\mathrm{SiO} \rightarrow \mathrm{SiOH}^{+}+\mathrm{H}_{2}$

$10^{-9} \quad-0.6$

16. $\mathrm{HCO}^{+}+\mathrm{SiO} \rightarrow \mathrm{SiOH}^{+}+\mathrm{CO}$

$10^{-9} \quad-0.6$

17. $\mathrm{He}^{+}+\mathrm{SiO} \rightarrow \mathrm{O}^{+}+\mathrm{Si}+\mathrm{He}$

$B_{1} \times 10^{-9} \quad-0.6$

$\mathrm{He}^{+}+\mathrm{SiO} \rightarrow \mathrm{O}+\mathrm{Si}^{+}+\mathrm{He}$

$B_{2} \times 10^{-9} \quad-0.6$

$\mathrm{He}^{+}+\mathrm{SiO} \rightarrow \mathrm{SiO}^{+}+\mathrm{He}$

$B_{3} \times 10^{-8} \quad-0.6$

18. $\mathrm{He}^{+}+\mathrm{SiO}_{2} \rightarrow \mathrm{SiO}^{+}+\mathrm{O}+\mathrm{He}$

$b_{1} \times 10^{-9} \quad-0.6$

$\mathrm{He}^{+}+\mathrm{SiO}_{2} \rightarrow \mathrm{Si}^{+}+\mathrm{O}_{2}+\mathrm{He} \quad b_{2} \times 10^{-9} \quad-0.6$

$\mathrm{He}^{+}+\mathrm{SiO}_{2} \rightarrow \mathrm{O}^{+}+\mathrm{SiO}+\mathrm{He} \quad b_{3} \times 10^{-9} \quad-0.6$

$\mathrm{He}^{+}+\mathrm{SiO}_{2} \rightarrow \mathrm{SiO}_{2}^{+}+\mathrm{He}$

$b_{4} \times 10^{-9} \quad-0.6$

19. $\mathrm{C}^{+}+\mathrm{SiO} \rightarrow \mathrm{CO}+\mathrm{Si}^{+}$

$10^{-9} \quad-0.6$

20. $\mathrm{C}^{+}+\mathrm{SiO}_{2} \rightarrow \mathrm{CO}+\mathrm{SiO}^{+}$

$10^{-9} \quad-0.6$

21. $\mathrm{Si}^{+}+\mathrm{e} \rightarrow \mathrm{Si}+\mathrm{h} \nu$

$8.7 \times 10^{-12 g} \quad-0.65$

22. $\mathrm{SiOH}^{+}+\mathrm{e} \rightarrow \mathrm{SiO}+\mathrm{H}$

$3.0 \times 10^{-7} \quad-0.5$

23. $\mathrm{SiO}_{2} \mathrm{H}^{+}+\mathrm{e} \rightarrow \mathrm{SiO}_{2}+\mathrm{H}$

$3.0 \times 10^{-7} \quad-0.5$

24. $\mathrm{SiH}_{2}^{+}+\mathrm{e} \rightarrow \mathrm{SiH}+\mathrm{H}$

$3.0 \times 10^{-7} \quad-0.5$

25. $\mathrm{H}^{+}+\mathrm{SiO} \rightarrow \mathrm{SiO}^{+}+\mathrm{H}$

$10^{-10}$

26. $\mathrm{H}^{+}+\mathrm{SiO}_{2} \rightarrow \mathrm{SiO}_{2}^{+}+\mathrm{H}$

$10^{-10}$

27. $\mathrm{Si}^{+}+\mathrm{A} \rightarrow \mathrm{A}^{+}+\mathrm{H}$

$10^{-10 h}$

28. $\mathrm{Si}^{+}+\mathrm{PM}^{-} \rightarrow \mathrm{Si}+\mathrm{PM}$

$2.4 \times 10^{-8 i} \quad-0.5$ 
a The units for cosmic ray induced UV photodestruction are $\mathrm{s}^{-1}$; the units for all other rate coefficients are $\mathrm{cm}^{3} \mathrm{~s}^{-1}$. The numerical values are for $T=300 \mathrm{~K}$. If the temperature dependence is a power law, the exponent is given in column 3 ; the symbol exp indicates the temperature dependence is $\exp (-111 / T)$.

${ }^{b}$ Measured by Swearengen et al. (1978).

c Measured by Husain and Norris et al. (1978).

${ }^{d}$ The rates for cosmic ray induced UV photodestruction are based on the work of Gredel, Lepp, and Dalgarno (1988).

- Fahey et al. (1981)

$f$ Anicich and Huntress (1986).

- Péquignot and Aldrovandi (1986).

${ }^{h}$ A stands for atoms that charge exchange rapidly with $\mathrm{Si}$, such as $\mathrm{Mg}$, $\mathrm{Fe}, \mathrm{Al}, \mathrm{Ca}$, and $\mathrm{Ni}$. The abundance of these atoms in dense clouds may be of the order of $10^{-6}$.

i Omont (1986). 
Table 3

Coefficients $P_{i}$ and $D_{i}$

\begin{tabular}{|c|c|c|}
\hline Symbol & Expression & Order of Magnitude \\
\hline$P_{1}$ & $k_{1} x(O H)+k_{2} x\left(\mathrm{O}_{2}\right)$ & $10^{-15}$ \\
\hline$P_{2}$ & $k_{10} x\left(\mathrm{H}_{2} \mathrm{O}\right)$ & $2 \times 10^{-16}$ \\
\hline$P_{3}$ & $b_{1} k_{18} x\left(\mathrm{He}^{+}\right)$ & $3 \times 10^{-19}$ \\
\hline$P_{4}$ & $g_{c r u v}(\mathrm{Si})$ & $3 \times 10^{-19}$ \\
\hline$P_{8}$ & $B_{1} k_{17} x\left(\mathrm{He}^{+}\right)$ & $3 \times 10^{-19}$ \\
\hline$P_{6}$ & $b_{2} k_{18} x\left(\mathrm{He}^{+}\right)$ & $3 \times 10^{-20}$ \\
\hline$P_{7}$ & $k_{3} x(O H)$ & $3 \times 10^{-18}$ \\
\hline$D_{1}$ & $\begin{array}{l}k_{27} x(\mathrm{~A})+k_{28} x\left(\mathrm{PM}^{-}\right) \\
+k_{10} x\left(\mathrm{H}_{2} \mathrm{O}\right)+0.5 k_{8}\end{array}$ & $5 \times 10^{-15}$ \\
\hline$D_{2}^{6}$ & $\begin{array}{c}k_{3} x(\mathrm{OH})+k_{17} x\left(\mathrm{He}^{+}\right) \\
+g_{c r u v}(\mathrm{SiO})+k_{19} x\left(\mathrm{C}^{+}\right)\end{array}$ & $4 \times 10^{-18}$ \\
\hline$D_{3}^{b}$ & $\begin{array}{c}k_{18} x\left(\mathrm{He}^{+}\right)+g_{\text {cruv }}\left(\mathrm{SiO}_{2}\right) \\
+k_{20} x\left(\mathrm{C}^{+}\right)\end{array}$ & $6 \times 10^{-19}$ \\
\hline
\end{tabular}

a The order of magnitude estimates are based on the following parameters: $n\left(\mathrm{H}_{2}\right)=10^{5} \mathrm{~cm}^{-3}, T=100 \mathrm{~K}$ and $\zeta=10^{-17} \mathrm{~s}^{-1} ; x\left(\mathrm{H}_{2} \mathrm{O}\right)=10^{-6}$, $x\left(\mathrm{O}_{2}\right)=3 \times 10^{-6}, x(\mathrm{OH})=3 \times 10^{-8}, x(\mathrm{~A})=10^{-6}$, and $x\left(\mathrm{PM}^{-}\right)=10^{-7}$. ${ }^{b} g_{\text {cruv }} \equiv G_{\text {cruv }} / n\left(\mathrm{H}_{2}\right)$. 


\section{REFERENCES}

Anicich, V. G. and Huntress, W. T. 1986, Ap. J. Suppl., 62, 553.

Bohme, D. K., Wlodek, S. and Fox, A.E. 1988, Rate Coefficients in Astrophysics, eds. T. J. Millar and D. A. Williams, (Kluwer, Dordrecht), p. 193.

Cernicharo, J., Gottlieb, C. A., Guélin, M., Thaddeus, P., and Vritlek, J. M. 1989, Ap. J. Letters in press.

Clary, D. C. 1988, Rate Coefficients in Astrophysics, eds. T. J.

Millar and D. A. Williams, (Kluwer/Dordrecht), p. 1.

Clegg, R. E. S., van Ijzendoorn, L. J., and Allamandola, L. J. 1983, M.N.R.A.S., 203, 125.

Crutcher, R. M. 1979 Ap. J., 234, 881.

Curtiss, L. A. and Pople, J. A. 1988, Chem. Phys. Letts., 144, 38.

Dalgarno, A. 1988, Physical Processes in Interstellar Clouds, eds. G. Morfill and M. S. Scholer (Reidel, Dordrecht).

Fahey, et al. 1981, J. Chem. Phys., 75, 669.

Flower, D. R., 1989, preprint.

Goldsmith, P. F., Snell, R. L., Erickson, N. F., Dickman, R. L., Schloerb, F. P., and Irvine, W. M. 1985, Ap. J., 289, 613.

Graff, M. M. 1989, Ap. J., 339, 239.

Gredel, R., Dalgarno, A., and Lepp, S. 1987, Ap. J. Letters, 323, L137.

Hartquist, T. W., Oppenheimer, M., and Dalgarno, A. 1980, Ap. J., 310, 182.

Hudson, R. D. 1971, Revs. Geophys. Sp. Phys., 9, 1.

Husain, D. and Norris, P. E. 1978, J. Chem. Soc. Far. Trans. II, 71,525 .

Irvine, W. M., Schloerb, Hjalmarson, A., and Herbst, E. 1985, Protostars and Planets II, Eds. D. C. Black and Mathews, M. S. (Arizona), p. 579. 
Knacke, R. F., Larson, H. P., and Noll, K. S. 1989, Ap. J. Letters, 335, 227.

Langer, W. D. and Graedel, T. E. 1988, Ap. J. Suppl., 69, 241.

Liszt, H. S. and Vanden Bout, P. A. 1985, Ap. J., 291, 178.

Millar, T. J. 1980, Ap. Sp. Sci., 72, 509.

Morris, M., Gilmore, W., Palmer, P., Turner, B. E., and Zuckerman, B. Ap. J. Letters, 199, L47.

Monteiro and Flower 1987, M.N.R.A.S., 228, 101.

Neufeld, D. A. and Dalgarno, A. 1989, Ap. J., 340, 369.

Omont, A. 1986, Astr. Ap., 169, 159.

Péquignot, D. and Aldrovandi, S. M. V. 1988 Astr. Ap., 161, 169.

Prasad, S. S. and Tarafdar, S. P. 1983, Ap. J., 267, 603.

Prasad, S. S. and Huntress, W. T. Jr., 1980, Ap. J. Suppl., 43, 1.

Scalo, J. M. and Slavsky, D. B. 1980, Ap. J. Letters, 239, L73.

Sternberg, A., Dalgarno, A. and Lepp, S. 1987, Ap. J., 320, 676.

Solomon, P. M. and Klemperer, W. 1972, Ap. J., 178, 125.

Swearengen, P. M., Davies, S. J., and Niemczyk, T. N. 1978, Chem. Phys. Letts., 55, 274.

Turner, J. L. and Dalgarno, A. 1977, Ap. J., 213, 386.

Tielens, A. G. G. M. and Hollenbach, D. J., 1985, Ap. J., 291, 722

Wilson, R. W., Jefferts, K. B., and Penzias, A. A., 1970, Ap. J. Letters, 161, L43.

Wilson, R. W., Penzias, A. A., Jefferts, K. B., Kutner, M. L. and Thaddeus, 1971, Ap. J. Letters, 167, L97.

Ziurys, L. M., Friberg, P., and Irvine, W. M. 1989, Ap. J., 343, 201. 


\section{FIGURE CAPTIONS}

Figure 1. Simplified schematic diagram of interstellar SiO chemistry showing the principle production routes and the destruction of neutrals by cosmic ray produced UV radiation (signified by the label $\nu$ ). Ionic destruction has been omitted for simplicity.

Figure 2. Fraction of silicon in the form of $\mathrm{SiO}$ in steady state as a function of temperature (plotted as $1 / T$ along the lower axis and $T$ along the upper). Three measures of the relative strength of the neutral production, $R f$, are shown and two of the ion contribution, $Z$. A nearly exponential decrease of SiO with decreasing $T$ down to $15 \mathrm{~K}$ requires weak ion $\left(Z \leq 10^{-3}\right)$ and moderate neutral $(R f \approx 1)$ production, consistent with conditions expected in dense regions of interstellar clouds.

Figure 3. Fraction of silicon in the form of $\mathrm{SiO}$ as a function of temperature (plotted as $1 / \mathrm{T}$ along the lower axis and $\mathrm{T}$ on the upper scale) at different times for $R f=1$ and no ion contribution $(Z=0) ; n=5 \times 10^{4} \mathrm{~cm}^{-3}, x\left(\mathrm{O}_{2}\right)=$ $3 \times 10^{-6}$, and $x(\mathrm{OH})=3 \times 10^{-8}$. Results including ions $\left(Z=10^{-3}\right)$ are shown for $10^{7} \mathrm{yr}$ and steady state. Below $30 \mathrm{~K}$, very long times are needed to approach equilibrium and, thus, even with contributions from ions, the solution looks like an exponential for $T>15 K$ over times that are relatively long compared with cloud dynamical times.

Figure 4. Similar to Figure 3 for (a) $n=2 \times 10^{5} \mathrm{~cm}^{-3}(R f \simeq 20)$ and (b) $n=10^{6} \mathrm{~cm}^{-3}(R f \simeq 200)$. 
AUTHORS ADDRESSES

A. E. Glassgold

Department of Physics

2 Washington Place

New York University

New York, NY 10003

William D. Langer

Princeton University

PO Box 451

Princeton, NJ 08543 
$H$
$\dot{\theta}$

$n$
0
0
0
0
$\neq$

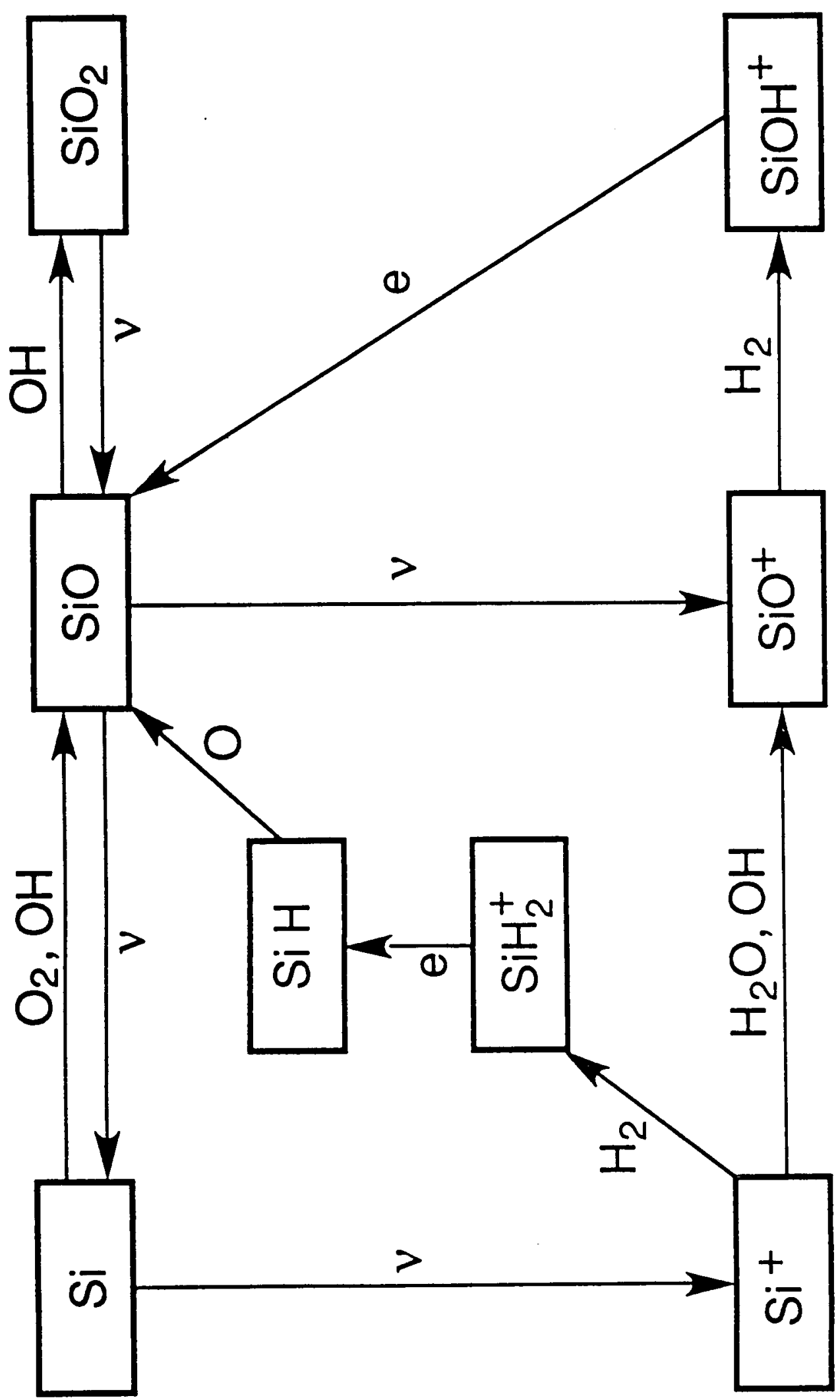




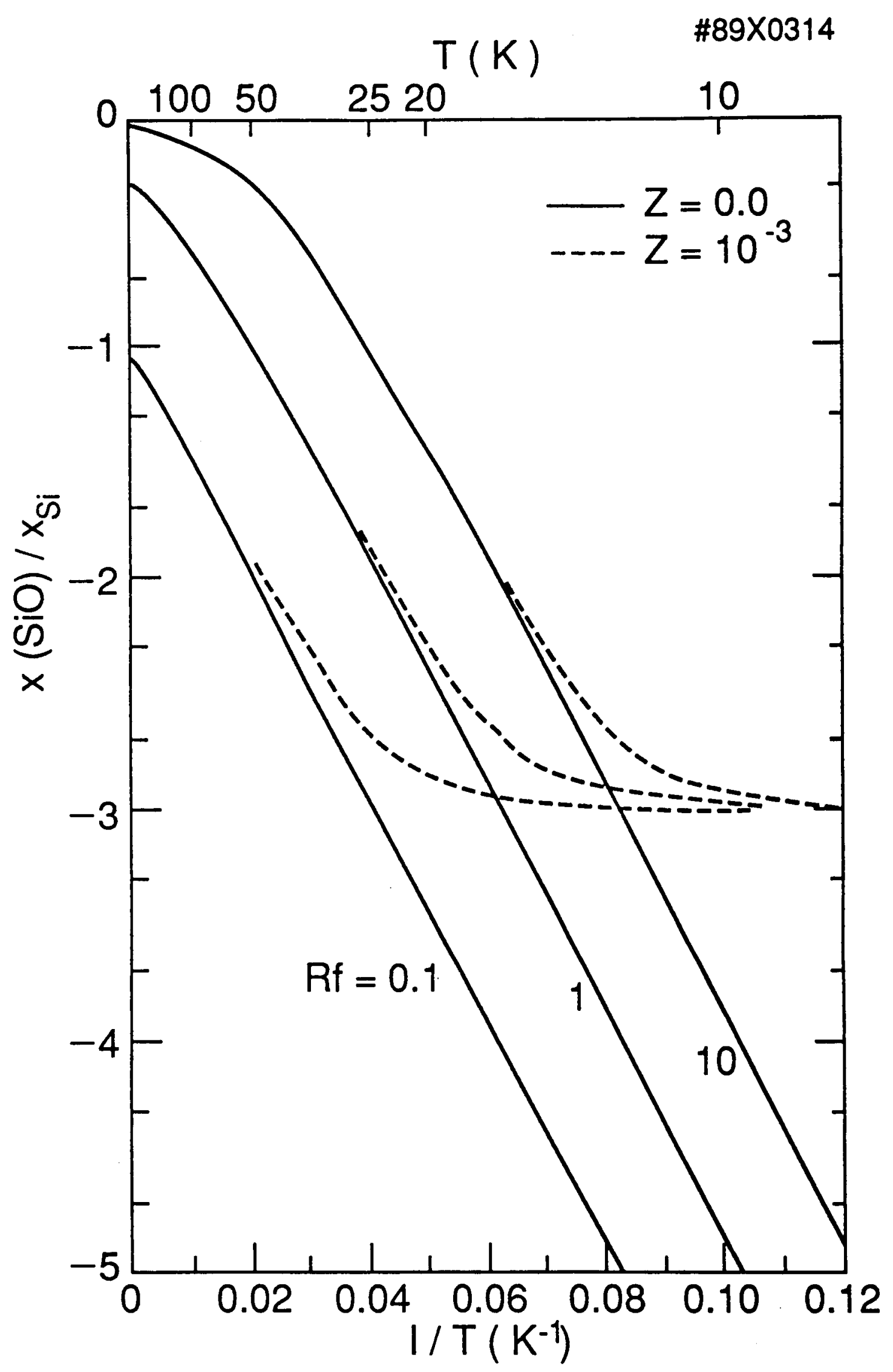

Fig. 2 


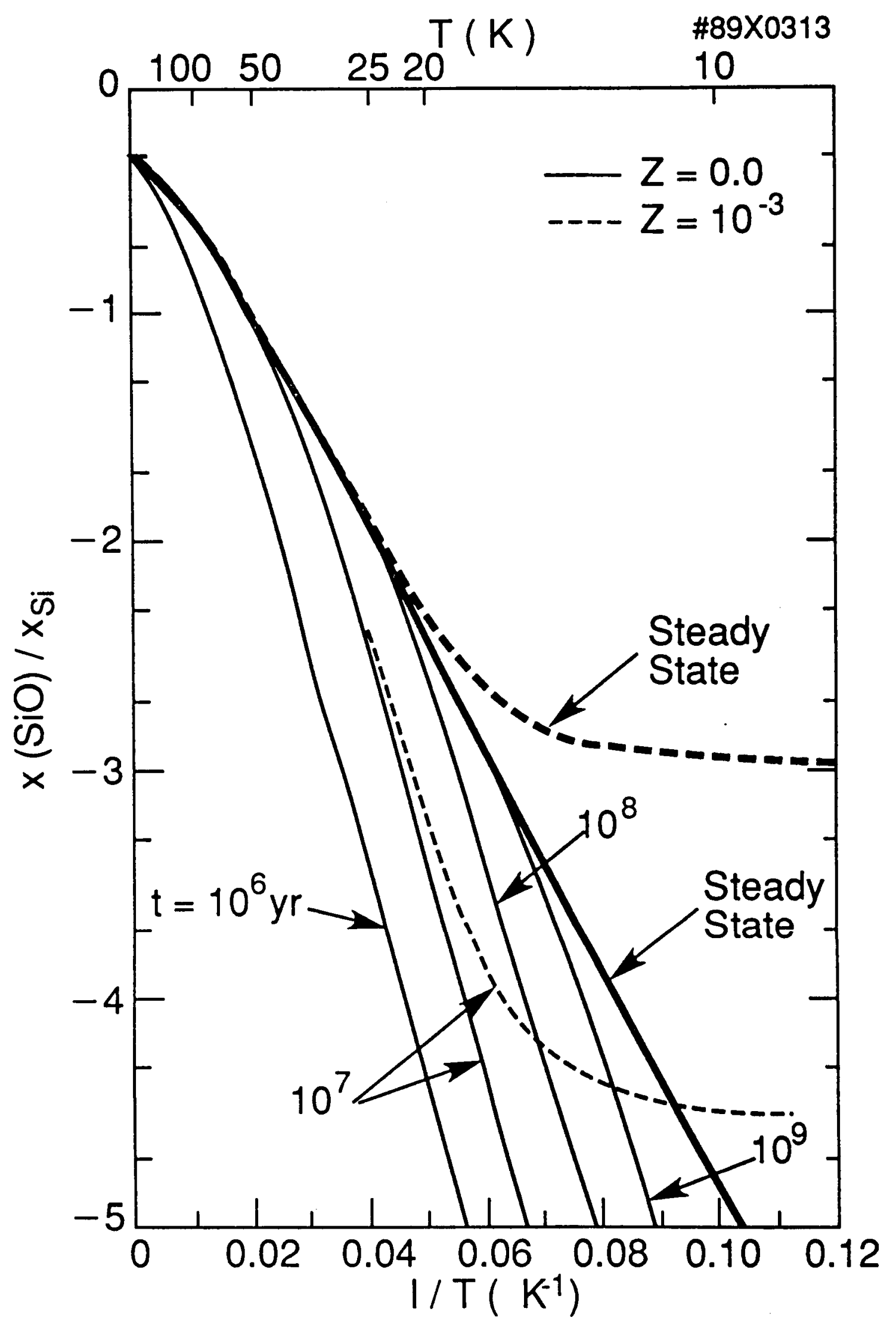

Fig. 3 


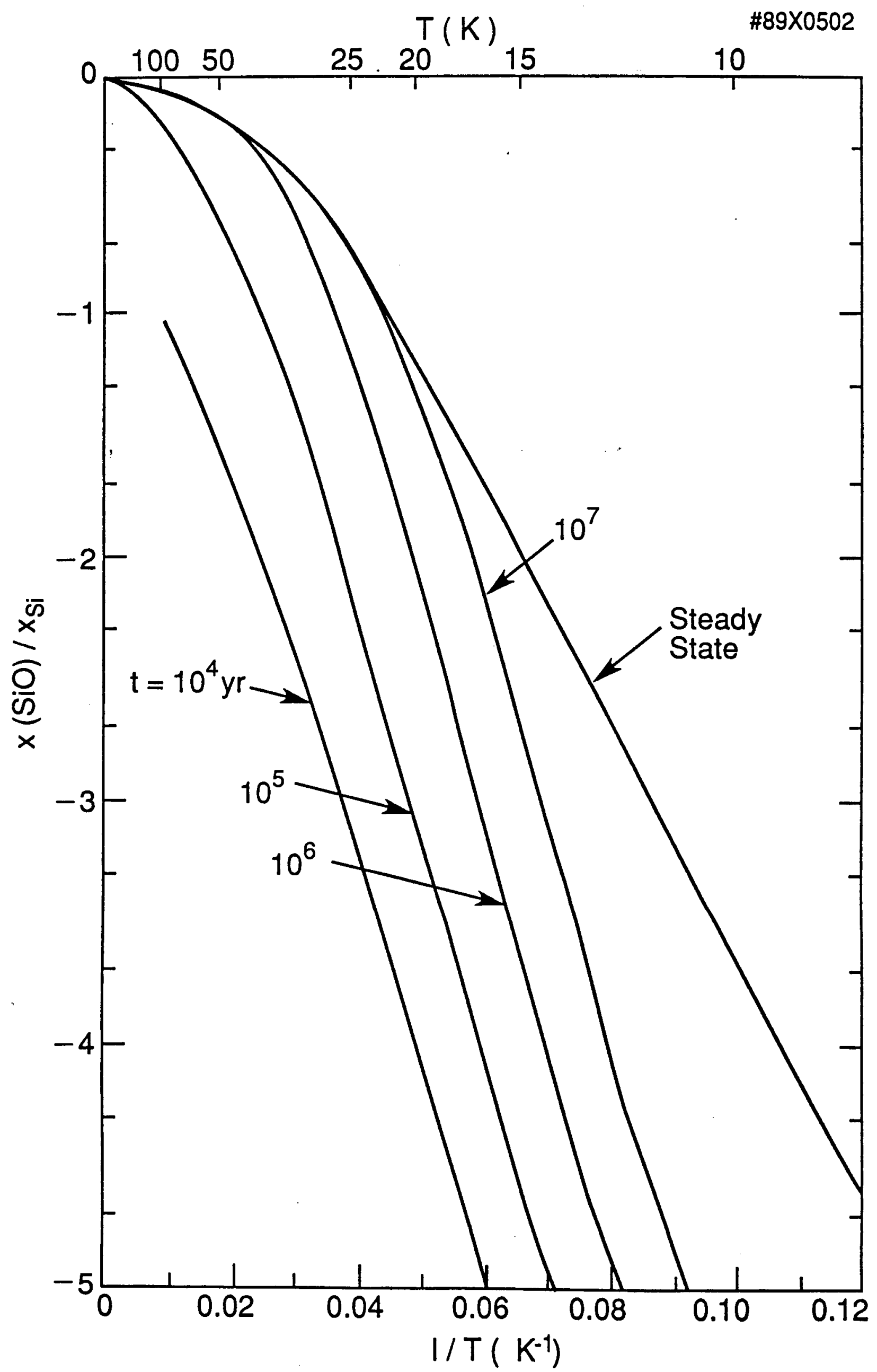

$F$ ig. $4 a$ 


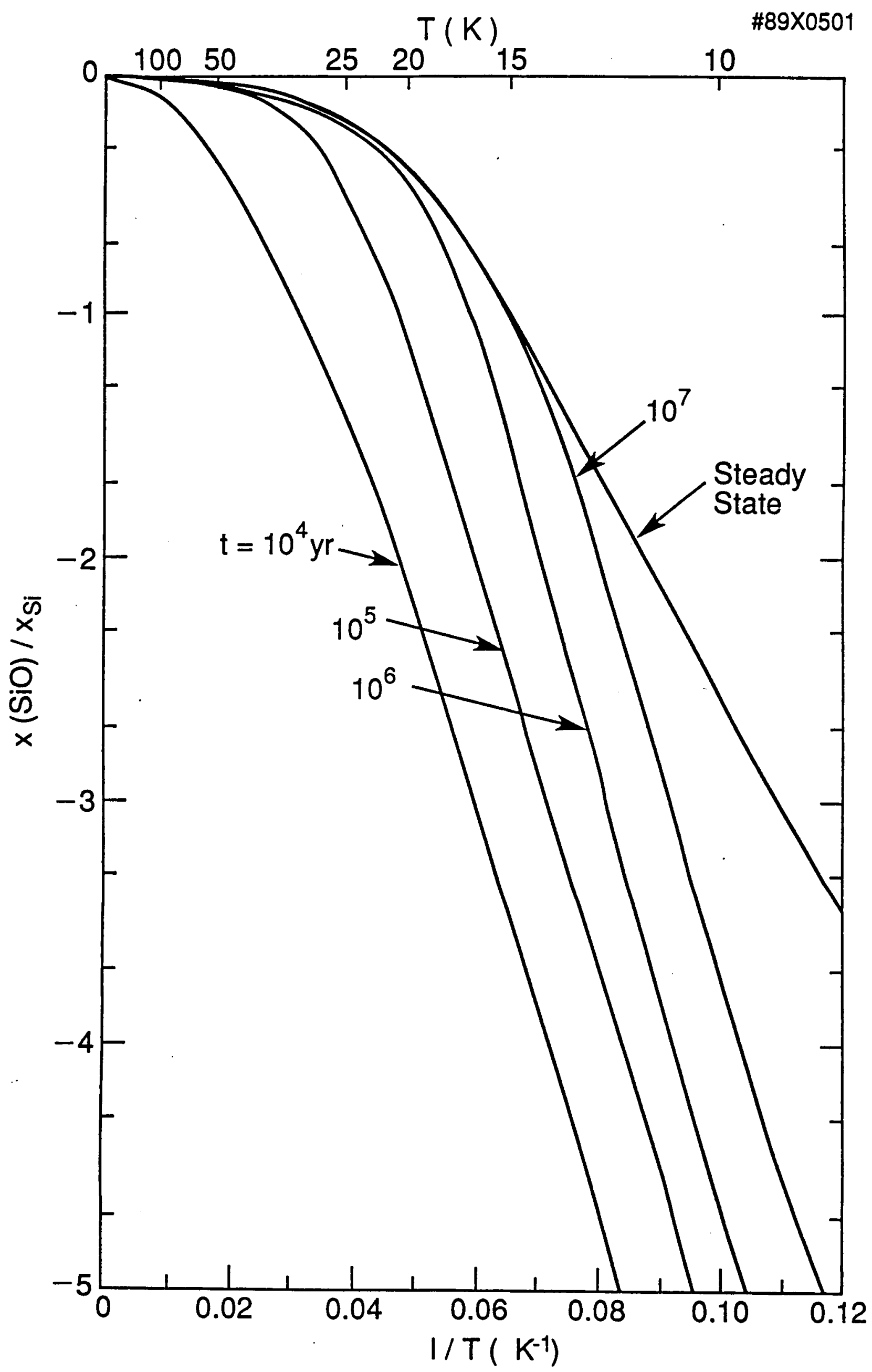

$F_{\text {ig }} 4 b$ 